\title{
SOBRE O CONCEITO PRELIMINAR DE CURSO: CONCEPČ̃̃O, APLICAÇÃO E MUDANÇAS METODOLÓGICAS
}

CAMILA YURI SANTANA IKUTA

\section{RESUMO}

O artigo apresenta uma revisão bibliográfica e documental sobre 0 Conceito Preliminar de Curso (CPC), considerado o indicador oficial de qualidade da educação superior para os cursos de graduação no país. O levantamento indica que o CPC passou por diversas revisões metodológicas desde sua criação, visando a aperfeiçoar as dimensões avaliadas. Entretanto, os principais debates científicos em torno do tema questionam diversos aspectos do indicador, como a dispensa automática das avaliações presenciais dos cursos; a formulação, padronização e o peso dos componentes; a alta participação dos discentes na nota final; a questão da heterogeneidade de Instituições de Ensino Superior e cursos existentes ser desconsiderada; entre outros. Nesse sentido, são propostas algumas reflexões, partindo de uma perspectiva crítica, visando a entender quais são as fragilidades e as potencialidades do CPC na avaliação da qualidade dos cursos superiores.

PALAVRAS-CHAVE INDICADORES EDUCACIONAIS - CONCEITO PRELIMINAR DE CURSO • CPC • SINAES • ENSINO SUPERIOR. 


\section{SOBRE EL CONCEPTO PRELIMINAR DE CURSO: CONCEPCIÓN, APLICACIÓN Y CAMBIOS METODOLÓGICOS \\ RESUMEN}

El artículo presenta una revisión bibliográfica y documental del Concepto Preliminar de Curso (CPC), considerado como el indicador oficial de calidad de la educación superior para los cursos de graduación en el país. El levantamiento indica que el CPC pasó por diversas revisiones metodológicas desde su creación, con miras a perfeccionar las dimensiones evaluadas. Sin embargo, los principales debates científicos alrededor del tema cuestionan diversos aspectos del indicador, como la exención automática de las evaluaciones presenciales de los cursos; la formulación, estandarización y peso de los componentes; la alta participación de los estudiantes en la nota final; la cuestión de que la heterogeneidad de Instituciones de Educación Superior y cursos existentes no se considere, entre otros. En este sentido se proponen algunas reflexiones, partiendo de una perspectiva crítica, a fin de entender cuáles son las fragilidades y las potencialidades del CPC en la evaluación de la calidad de los cursos superiores.

PALABRAS CLAVE INDICADORES EDUCACIONALES - CONCEPTO PRELIMINAR

DE CURSO • CPC • SINAES • EDUCACIÓN SUPERIOR.

\section{ON PRELIMINARY COURSE CONCEPT: DESIGN, IMPLEMENTATION AND METHODOLOGICAL CHANGES}

ABSTRACT

The article presents a bibliographical and documentary review of Course Preliminary Concept (CPC), considered the official indicator of quality in higher education for undergraduate courses in the country. The survey indicates that CPC underwent several methodological revisions since its creation to optimize the scope assessed. However, the main scientific debate on the topic questions several aspects of this indicator, such as automatic exemption from in-person tests; the development, standardization and weighting of the components; the high participation of students in the final grade; the disregard for the issue of diversity of higher education institutions and existing courses; among others. In this sense, we propose some reflections from a critical perspective in order to understand the weaknesses and potentials of CPC in the quality assessment of higher education courses.

KEYWORDS EDUCATIONAL INDICATORS - PRELIMINARY COURSE CONCEPT • CPC $・$ SINAES $\cdot$ HIGHER EDUCATION. 


\section{INTRODUÇÃO}

O presente texto discute o Conceito Preliminar de Curso (CPC), um indicador elaborado no âmbito do Ministério da Educação (MEC), considerado, oficialmente, o Indicador de Qualidade da Educação Superior voltado aos cursos superiores brasileiros. Para seu cálculo, são consideradas três dimensões em relação aos cursos: desempenho dos estudantes, indicadores do corpo docente e condições oferecidas para o desenvolvimento do processo formativo.

Para subsidiar essa discussão, foi realizada uma revisão bibliográfica e documental, a partir de uma perspectiva crítica, sobre a concepção, aplicação e mudanças metodológicas do CPC. O texto foi organizado em quatro partes: 1) breve apresentação sobre o Sistema Nacional de Avaliação da Educação Superior (Sinaes), que engloba os eixos de avaliação de cursos, estudantes e instituições; 2) processos que nortearam a concepção e aplicação do CPC; 3) aspectos metodológicos do cálculo do indicador (componentes e fórmulas), bem como as revisões metodológicas realizadas desde seu surgimento; e 4) debates travados pela produção científica em tor- 
no do tema, que indicam alguns dos limites e possibilidades de sua utilização, seguindo-se das considerações finais.

\section{- Sistema nacional de aVAliação da educação SUPERIOR (SINAES)}

O Sinaes é o sistema de avaliação atualmente vigente no país. Foi instituído em 2004, com o objetivo de realizar um processo de avaliação da educação superior orientado em três eixos: avaliação das instituições, dos cursos de graduação e do desempenho acadêmico dos estudantes, possuindo como uma de suas finalidades "a melhoria da qualidade da educação superior” (BRASIL, 2004, art. $1^{\circ}, \S 1^{\circ}$ ). É operacionalizado pelo Instituto Nacional de Estudos e Pesquisas Educacionais Anísio Teixeira (Inep).

Para concretizar a proposta de um sistema de avaliação integrado, a Lei do Sinaes previu o estabelecimento de mecanismos de avaliação institucional (autoavaliação e avaliação externa); a avaliação de cursos de graduação, contemplando, entre outros aspectos, visitas presenciais de comissões de especialistas, por áreas de conhecimento; e a avaliação dos estudantes, por meio de uma prova de larga escala, o Exame Nacional de Desempenho dos Estudantes (Enade).

A criação de um sistema amplo de avaliação interna e externa educacional, inclusive para promover melhorias nos processos acadêmicos, fazia parte das metas e objetivos previstos do Plano Nacional de Educação (PNE) 2001-2010 (DIAS SOBRINHO, 2008). Ainda, o Sinaes foi proposto de maneira ampla e diversificada em suas premissas, visando a articulação entre várias

[...] dimensões educativas e institucionais, diferentes metodologias, procedimentos, objetos e objetivos, instâncias da comunidade acadêmico-científica e do Estado, autoavaliação e avaliação externa, autorregulação e regulação etc. (DIAS SOBRINHO, 2008, p. 820)

Portanto, o tripé de avaliação seria baseado na combinação de diferentes aspectos metodológicos, instrumentos e operações (LACERDA, 2015). 
10 Enade é realizado anualmente desde 2004. O exame busca aferir entre outras questões, o desempenho dos estudantes em relação às diretrizes curriculares dos cursos e de competências em temas exteriores, como realidade brasileira e mundial (BRASIL, 2004, art. 5ㅇ, § 1º)

2 Avaliadores inscritos no Banco de Avaliadores do Sistema Naciona de Avaliação da Educação Superior (BASis)
No entanto, desde sua criação, entraram em vigor diversas medidas que alteraram esse percurso. Vale destacar, por exemplo, o Decreto n. 5.773, editado em 2006 - mais conhecido como "decreto-ponte" entre avaliação e regulação -, que realizou algumas mudanças em relação à organização da educação superior, entre elas a articulação dos instrumentos de regulação, avaliação e supervisão, atrelando esses aspectos à nova regulamentação do Sinaes. Dentre essas mudanças estão, por exemplo, a atribuição de responsabilidade às Secretarias do MEC e do Conselho Nacional de Educação para os atos de credenciamento/autorização e recredenciamento dos cursos e instituições, enfatizando o papel da fiscalização (BARREYRO; ROTHEN, 2014); e atribuiu ao Inep a competência de elaborar instrumentos de avaliação para o credenciamento de instituições e autorizações de cursos. Esses processos seguiram a tendência de "separar a autoavaliação da avaliação externa, retirando assim a centralidade da autoavaliação", estabelecendo fronteiras mais claras entre os processos de avaliação e regulação (BARREYRO; ROTHEN, 2006, p. 970).

Não obstante, como será exposto mais à frente, esse processo se intensificou com a maior ênfase dada, no decorrer da operacionalização do Sinaes, aos resultados da prova de larga escala do Enade, ${ }^{1}$ bem como à criação de elementos quantitativos derivados desse exame, na forma de indicadores, para a avaliação de estudantes, cursos e instituições, em um processo de reforço das práticas de fiscalização e supervisão no sistema. Ou seja, o Sinaes foi se distanciando cada vez mais de suas propostas originais.

É possível perceber esse movimento, de forma clara, na concretização do eixo de avaliação dos cursos de graduação, cuja Lei do Sinaes previu a utilização de "procedimentos e instrumentos diversificados" (BRASIL, 2004, art. $4^{\circ}$, § $1^{\circ}$ ), considerando em especial as dimensões dos cursos relativas ao corpo docente, instalações físicas e recursos didático-pedagógicos, para as quais a visita de avaliadores externos (comissão de especialistas ${ }^{2}$ das respectivas áreas de conhecimento) é colocada como obrigatória. No entanto, a avaliação de cursos ficou marcada pelo protagonismo de um indicador criado em 2008, denominado Conceito Preliminar de Curso, que será apresentado na próxima seção. 


\section{AVALIAÇÃO DE CURSOS NO SINAES: O CONCEITO PRELIMINAR DE CURSO}

Entre as diversas medidas criadas no âmbito do Sinaes, destaca-se, no ano de 2008, a criação do Conceito Preliminar de Curso, juntamente com o Índice Geral de Cursos Avaliados da Instituição (IGC), ${ }^{3}$ para dar prosseguimento e operacionalização aos eixos de avaliação de cursos e instituições. O surgimento desses índices está relacionado, entre outros fatores, à situação de represamento de processos de credenciamento de instituições e reconhecimento de cursos, especialmente durante os anos de 2003 a 2006, o que culminou na necessidade de medidas legais para resolver tais problemas (BARREYRO; ROTHEN, 2014).

Nesse âmbito, foi editada a Portaria Normativa MEC n. 40/2007 que, além de instituir o E-MEC (sistema eletrônico para gerenciar os processos de regulação, avaliação e supervisão da educação superior), também flexibilizou a necessidade da avaliação presencial para os processos de renovação de reconhecimento de cursos superiores. Consta também, dessa Portaria, que essa avaliação presencial poderia ser dispensada por meio do resultado de um novo indicador, na forma de um conceito preliminar. Esse conceito seria produzido a partir de informações das Instituições de Ensino Superior (IES) e dos cursos, dos Censos da Educação Superior e dos resultados do Enade.

Nesse movimento, visando a consolidar as disposições da Lei do Sinaes e da Portaria Normativa n. 40, a aplicação do conceito preliminar, posteriormente denominado Conceito Preliminar de Curso, foi regulamentada em agosto de 2008 pela Portaria Normativa MEC n. 4, que versa sobre a aplicação do conceito preliminar para fins dos processos de renovação de reconhecimento de cursos superiores.

O CPC é calculado e divulgado anualmente pelo Inep, cujos conceitos são emitidos em escala de cinco níveis, de 1 a 5 (assim como outros indicadores no âmbito do Sinaes), em que é considerado satisfatório o conceito igual ou superior a três, e insatisfatório o conceito inferior a três (BRASIL, 2008).

Ainda, o conceito satisfatório pode subsidiar ou até mesmo dispensar a necessidade de avaliação presencial: “os cursos
3 Índice Geral de Cursos Avaliados da Instituição (IGC), indicador utilizado para avaliar as Instituições de Ensino Superior, calculado considerando a média dos conceitos dos cursos de graduação (CPCS) em cada IES e de indicadores relativos aos programas de pós-graduação. 
que tenham obtido conceito preliminar satisfatório ficam dispensados de avaliação in loco nos processos de renovação de reconhecimento respectivos" (BRASIL, 2008, art. $2^{\circ}$ ). Nesses casos, é facultativo às IES o requerimento da visita, caso queiram modificar ou confirmar o CPC atribuído previamente. Esse fato foi responsável por reduzir, de forma significativa, o número de visitas realizadas pelas comissões de especialistas após a criação desses indicadores (BARREYRO; ROTHEN, 2011). Por outro lado, se a nota final do CPC for inferior a três (considerada insatisfatória), o curso, obrigatoriamente, deve submeter-se à avaliação presencial, ou será considerado em situação irregular.

Por possuir um caráter preliminar, como o próprio nome sugere, a intenção é que o CPC possa subsidiar esses processos de avaliação in loco realizados por esses especialistas nas instituições de ensino (BRASIL, 2013a). Quando o CPC serve de subsídio para os processos de avaliação presenciais, essas avaliações resultam em outro conceito: o Conceito de Curso (CC) (BRASIL, 2010, art. 33-C). Entretanto, na prática, foi observado que o CPC acabou se tornando o indicador definitivo na maioria dos casos, por conta da dispensa automática da avaliação presencial, muito em razão das dificuldades do MEC e do Inep de operacionalizar esse aspecto (NUNES; FERNANDES; ALBRECHT, 2014).

De fato, a questão da necessidade de avaliação por meio de visitas presenciais, prevista no Sinaes desde 2004, tornou-se um dilema para todo o processo de avaliação da educação superior, se considerada a grande expansão do segmento ocorrida no Brasil. Segundo os dados dos Censos da Educação Superior (Inep), o país contava, em 1996, com 922 IES e 6.644 cursos de graduação (presencial e a distância), expandindo-se, em 2014, para 2.368 IES (variação de 157\%) e 32.878 cursos (variação de 395\%). Segundo a visão de especialistas do Inep,

[...] ao dispensar da visita os cursos com indicador $3,4 \mathrm{e}$

5, o CPC viabiliza as avaliações in loco e, por servir de guia para os avaliadores, induz uma maior coerência entre essas avaliações e os indicadores objetivos de qualidade. (FERNANDES et al., 2009, p. 6)

Entretanto, as consequências da dispensa da visita presencial podem ser observadas por outra perspectiva. Segundo 
Barreyro e Rothen (2011), na ocasião da criação do CPC em 2008, a tendência era de que essas avaliações fossem reduzidas praticamente pela metade. Com essa medida, o MEC

[...] parece visar diminuir o número de cursos a receberem avaliação externa [...] e, assim, aligeirar o processo de reconhecimento de cursos, perdendo espaço a avaliação formativa e o rigor regulatório. (BARREYRO; ROTHEN, 2011, p. 31)

Ainda, os autores reforçam que essa modalidade de avaliação de cursos, obrigatória na Lei do Sinaes, foi dispensada na Portaria Normativa que regulamentou a aplicação do CPC, ou seja, a Lei foi desrespeitada por uma Portaria, que possui menor hierarquia jurídica (BARREYRO; ROTHEN, 2014).

Apesar de estar em vigor desde 2008, o CPC somente foi oficializado como Indicador de Qualidade na Educação Superior voltado aos cursos de graduação com a republicação de 2010 da Portaria Normativa MEC n. 40, em que consta:

São indicadores de qualidade, calculados pelo Inep, com base nos resultados do Enade e demais insumos constantes das bases de dados do MEC, segundo metodologia própria, aprovada pela Conaes, atendidos os parâmetros da Lei n. 10.861, de 2004:

I - de cursos superiores: o Conceito Preliminar de Curso (CPC), instituído pela Portaria Normativa n. 4 , de 5 de agosto de 2008; [...]. (BRASIL, 2010, art. 33-B, grifo nosso)

De fato, para o Inep, os indicadores de qualidade da educação superior (CPC, IGC e Conceito Enade) " "têm se constituído em importantes medidas” (BRASIL, 2014, p. 5) para as ações da Secretaria de Regulação e Supervisão da Educação Superior (Seres), situação em que se verifica que essa Secretaria

[...] tem publicado diversas Instruções Normativas aplicando medidas regulatórias (como a abertura de Protocolos de Compromisso e suspensão da entrada de estudantes) para cursos e IES apenas com base no CPC e IGC. (BRASIL, 2014, p. 5)

Para o Instituto, o CPC e o IGC fazem parte das 
5 No CPC (assim como para o Conceito Enade), o cálculo do indicador é realizado por Unidade de Observação, ou Unidadei: "o cálculo [...] não é necessariamente realizado para o Curso, mas para a Unidade de Observação (Unidade), que consiste no conjunto de cursos que compõe uma área de avaliação específica do Enade de uma IES em um determinado município" (BRASIL, 2013a, p. 9, grifo do original)

6 A Conaes é um órgão que coordena e supervisiona o Sinaes, em que algumas de suas atribuições são: propor e avaliar as dinâmicas procedimentos e mecanismos da avaliação institucional, de cursos e de desempenho dos estudantes.
[...] medidas da qualidade dos cursos e das instituições do país, utilizados tanto como referenciais no desenvolvimento de políticas públicas para a Educação Superior quanto como fonte de consultas pela sociedade. (BRASIL, 2013a, p. 5)

\section{COMPONENTES DO CONCEITO PRELIMINAR DE CURSO}

O CPC possui como pilares as seguintes dimensões: desempenho dos estudantes, corpo docente, infraestrutura, instalações físicas, recursos didático-pedagógicos e oportunidades de ampliação da formação acadêmica e profissional dos cursos. Para o Inep, o

[...] propósito do CPC é agrupar diferentes medidas da qualidade do curso, entendidas como medidas imperfeitas da contribuição do curso para a formação dos estudantes, em uma única medida com menor erro. (BRASIL, 2013a, p. 14)

Esse indicador é calculado anualmente, no ano seguinte da realização do Enade de cada área, somente para alguns cursos superiores (por Unidade de Observação ${ }^{5}$ ), pois toma como base os mesmos cursos escolhidos para a avaliação do Enade - até mesmo por depender diretamente de seus resultados para a composição do Conceito, conforme será observado posteriormente. A escolha dos cursos que serão avaliados no Enade em determinado ano é realizada pela Comissão Nacional de Avaliação da Educação Superior (Conaes), ${ }^{6}$ observado o calendário de avaliação, em que o Enade é aplicado aos estudantes de cada área trienalmente (BRASIL, 2010, art. 33-E).

A primeira Nota Técnica formalizando as diretrizes para a aplicação do Conceito Preliminar de Curso na avaliação dos cursos superiores foi divulgada em 2008, pela Diretoria de Avaliação da Educação Superior (Daes) do Inep, referente aos indicadores calculados, pela primeira vez, em 2007 (BRASIL, 2014). Será verificado, mais adiante, que o indicador passou por uma série de mudanças metodológicas desde a sua criação.

A discussão dos critérios e ponderações relativos aos componentes do CPC é realizada por meio de estudos desenvolvidos pelo corpo técnico do Inep, discussões com a Seres/ MEC, Conaes e representantes de IES públicas e privadas in- 
teressadas (BRASIL, 2013a). No caso do CPC de 2014, foram contemplados ao todo oito componentes para o cálculo da nota final (BRASIL, 2013a):

- Desempenho dos Estudantes: notas dos concluintes no Enade e resultados do Indicador de Diferença entre os Desempenhos Observado e Esperado (IDD), que é composto por variáveis do Exame Nacional do Ensino Médio (Enem7), Enade e Questionários do Estudante do Enem e do Enade;

- Percepção Discente sobre Condições do Processo Formativo: respostas dos estudantes, no Questionário do Estudante do Enade, sobre as questões referentes à infraestrutura e instalações físicas, organização didático-pedagógica e oportunidades de ampliação da formação acadêmica e profissional dos cursos;

- Corpo Docente: número de funções docentes com titulação de mestrado e de doutorado, e regime de trabalho parcial ou integral. Informações obtidas por meio do Censo da Educação Superior.

A nota dos concluintes no Enade refere-se à mesma nota que dá origem ao Conceito Enade: "para cada Unidadei considera-se $75 \%$ da nota dos estudantes concluintes no componente específico do Enade e 25\% da nota dos mesmos estudantes no componente de formação geral do Enade" (BRASIL, 2013a, p. 18).

A nota atribuída em relação ao IDD (um indicador preexistente, criado no âmbito do Sinaes) visa a mensurar as diferenças em relação ao perfil dos estudantes ao ingressar e ao concluir o ensino superior, o que, segundo documentos oficiais, não é explicado somente pelas diferenças de qualidade entre os cursos (BRASIL, 2015). O IDD busca aferir

[...] aquilo que diz respeito especificamente ao valor agregado pelo curso ao desenvolvimento dos estudantes concluintes, considerando seus desempenhos no Enade e suas características de desenvolvimento ao ingressar no curso de graduação avaliado. (BRASIL, 2015, p. 6)
7 Enem, criado em 1998, avalia o desempenho dos estudantes ao final da educação básica. 
8 No caso do Questionário do Estudante Enade de 2014, os itens 41 $54,56,58,59$ a 65 e 68

9 No caso do Questionário do Estudante Enade de 2014, os itens 27 a $40,42,47$ a 51, 55, 57 e 66

10 No caso do Questionário do Estudante Enade de 2014, os itens 43 a 46, 52, 53 e 67. Conforme será discutido no decorrer do texto, esta variável foi instituída somente no ano de 2013, após uma reformulação do Questionário do Estudante.
Para Bittencourt et al. (2008, p. 254), o IDD surge "motivado pelo fato de que o perfil dos ingressantes varia entre os cursos e entre as IES, fazendo com que as notas dos concluintes tendam a refletir essas desigualdades".

Nesse sentido, utilizam-se diferentes variáveis, como desempenho de ingressantes e de concluintes, usando resultados do Enem e do Enade, nível de escolaridade dos pais dos ingressantes, razão entre o número de concluintes e ingressantes, entre outras (BITTENCOURT et al., 2008) para calcular a diferença entre a nota obtida pelos concluintes e a nota que seria esperada com relação aos ingressantes, de acordo com o perfil de um mesmo curso. Quando não for possível atribuir a nota do IDD para uma Unidadei (por não ser possível a estimativa de alguns parâmetros necessários ao cálculo), ela receberá o mesmo valor da nota de concluintes no Enade para o cálculo do CPC.

Sobre as notas atribuídas à percepção discente do processo formativo, para a nota relativa aos quesitos de infraestrutura e instalações físicas, são utilizados o número total de estudantes vinculados à Unidadei que responderam as questões referentes a esses temas no Questionário do Estudante do Enade, ${ }^{8}$ em que são gerados pesos diferentes para cada resposta, no cálculo da Nota de Infraestrutura do CPC (BRASIL, 2013a). Da mesma forma, são extraídas as notas relativas aos itens de Organização didático-pedagógica ${ }^{9}$ e de Oportunidades de ampliação da formação acadêmica e profissional ${ }^{10}$ (BRASIL, 2015).

As informações do corpo docente são extraídas do Censo da Educação Superior de cada ano, vinculando-os ao curso em que lecionam. O cálculo da titulação envolve o número total de docentes vinculados à Unidadei cuja titulação seja maior ou igual ao Mestrado e/ou Doutorado e o total de docentes dessa Unidade. A nota com relação ao regime de dedicação de trabalho (parcial ou integral) consiste no número total de docentes, vinculados à Unidadei, cujo regime de dedicação seja integral ou parcial e o número total de docentes dessa Unidade. 


\section{FÓRMULA ATUAL DO CONCEITO PRELIMINAR DE CURSO}

As notas de todos os componentes que integram o CPC são padronizadas, para que sigam uma escala de 0 a 5 , momento em que é adotado o recurso estatístico de afastamento padronizado, ${ }^{11}$ no qual se utilizam as médias e os desvios-padrão calculados por área de avaliação. Com isso, é realizada uma aproximação da nota dos componentes em relação à média nacional obtida pela área de avaliação.

Posteriormente, os resultados dos afastamentos padronizados são transformados em notas padronizadas para cada componente, que também podem variar de 0 a 5 . Utilizando como base todos os componentes descritos e padronizados, a forma de cálculo da nota contínua do CPC é obtida por meio de uma ponderação ${ }^{12}$ das notas de cada componente, ou seja, situação em que cada uma possui um peso diferente no resultado da nota final, conforme ilustram a fórmula (1) e a Tabela 1, referentes ao CPC de 2014:

$$
\begin{aligned}
& \mathrm{NCPC}_{j}=0,2 \mathrm{NC}_{j}+0,35 \mathrm{NIDD}_{j}+0,075 \mathrm{NM}_{j}+0,15 \mathrm{ND}_{j}+ \\
& 0,075 \mathrm{NR}_{j}+0,075 \mathrm{NO}_{j}+0,05 \mathrm{NF}_{j}+0,025 \mathrm{NA}_{j} \\
& \text { Fonte: Brasil (2015). }
\end{aligned}
$$

11 Realizado tomando-se “a medida original para cada Unidade i (por exemplo, a proporção de professores mestres dessa Unidade) e subtrai-se dela a média dessa medida obtida para a área de avaliação em nível nacional $J$ a qual esta Unidade pertence. Divide-se o resultado da subtração pelo desvio padrão da medida obtido para a área de avaliação em nível nacional J a qual esta Unidade pertence" (BRASIL. 2013a, p. 10)

12 As ponderações são estabelecidas a partir de estudos produzidos pela equipe técnica do Inep, e mediante "discussões com a Secretaria de Regulação e Supervisão da Educação Superior - Seres/MEC, Conaes e representantes de IES públicas e privadas interessadas" (BRASIL, 2013a, p. 18). Ressalta-se que os componentes, o peso e o cálculo sofreram modificações metodológicas

\begin{tabular}{|c|c|c|c|}
\hline \multicolumn{2}{|r|}{ COMPONENTES DO CPC } & \multicolumn{2}{|c|}{ PESO NA NOTA FINAL } \\
\hline \multirow{2}{*}{$\begin{array}{l}\text { Desempenho dos } \\
\text { Estudantes }\end{array}$} & Nota dos Concluintes no Enade (NC) & \multirow{2}{*}{$55 \%$} & $20 \%$ \\
\hline & $\begin{array}{l}\text { Nota do Indicador da Diferença entre os Desempenhos } \\
\text { Observado e Esperado (NIDD) }\end{array}$ & & $35 \%$ \\
\hline \multirow{3}{*}{$\begin{array}{l}\text { Percepção Discente sobre } \\
\text { o Processo Formativo }\end{array}$} & Nota referente à Organização Didático-Pedagógica (NO) & \multirow{3}{*}{$15 \%$} & $7,5 \%$ \\
\hline & Nota referente à Infraestrutura e Instalações Físicas (NF) & & $5,0 \%$ \\
\hline & $\begin{array}{l}\text { Nota referente às Oportunidades de Ampliação da } \\
\text { Formação Acadêmica e Profissional (NA) }\end{array}$ & & $2,5 \%$ \\
\hline \multirow{3}{*}{ Corpo Docente } & Nota de Proporção de Mestres (NM) & \multirow{3}{*}{$30 \%$} & $7,5 \%$ \\
\hline & Nota de Proporção de Doutores (ND) & & $15 \%$ \\
\hline & Nota de Regime de Trabalho (NR) & & $7,5 \%$ \\
\hline
\end{tabular}
em algumas edições do CPC.

TABELA 1 - Pesos dos componentes no Conceito Preliminar de Curso 2014

Fonte: Brasil (2015, p. 22).

Portanto, pode-se dizer que o CPC é uma média ponderada de diversas medidas, previamente estabelecidas, relativas à qualidade de um curso. Realizando a leitura dos valores da fórmula em percentuais (Tabela 1), observa-se que 35\% do 
peso é atribuído à Nota do Indicador de Diferença entre os Desempenhos Observado e Esperado (NIDD); outros 20\%, em relação à Nota dos Concluintes (NC), totalizando 55\% atribuído diretamente ao desempenho dos estudantes. A Nota de Infraestrutura (NF) possui peso de $5 \%$, a Nota de Organização Didático-Pedagógica (NO), 7,5\%, e a Nota referente às Oportunidades de Ampliação da Formação Acadêmica e Profissional (NA) representa $2,5 \%$; juntas, as três somam $15 \%$ de atribuições às respostas dos estudantes ao Questionário do Estudante do Enade. Com relação ao corpo docente, é atribuído um peso de $30 \%$, distribuído em $15 \%$ para a Nota de Professores Doutores (ND), 7,5\% para a Nota de Professores Mestres (NM) e 7,5\% para a Nota sobre Regime de Trabalho parcial/integral (NR).

Com isso, o resultado é a nota do CPC em valores contínuos, de cada unidade de observação (NCPCj), que posteriormente é arredondada para cima e apresentada por faixas (de 1 a 5 ), conforme ilustra a Tabela 2 :

TABELA 2 - Valores contínuos e valores por faixas do CPC 2014

\begin{tabular}{c|c}
\hline NCPC - VALOR CONTÍNUO & CPC - FAIXA \\
\hline $0 \leq N C P C j<0,945$ & 1 \\
\hline $0,945 \leq N C P C j<1,945$ & 2 \\
\hline $1,945 \leq N C P C j<2,945$ & 4 \\
\hline $2,945 \leq N C P C j<3,945$ & 5 \\
\hline $3,945 \leq N C P C j \leq 5$ &
\end{tabular}

Fonte: Brasil (2015, p. 23).

Nota: Os cursos com NCPC maior ou igual a 3,945 somente poderão atingir o valor máximo do indicador (faixa igual a 5) caso tenham obtido nota maior que 0,945 em todos os componentes.

Vale ressaltar que algumas Unidades de Observação ficam classificadas como Sem Conceito (SC), pois não atingiram os requisitos mínimos dos critérios estabelecidos para obter o CPC. Atualmente, são necessários no mínimo dois estudantes concluintes participantes do Enade (BRASIL, 2015).

Em termos operacionais, o CPC 2014 gerou resultados para 9.963 cursos de 43 áreas, distribuídos em 8.959 Unidades de Observação, em 1.762 IES. No panorama geral, por um lado, 85,7\% dos cursos apresentaram desempenho satisfatório, ou seja, com conceitos 3, 4 e 5. Por outro lado, 14,3\% 
desses cursos foram considerados insatisfatórios, e deveriam passar por avaliação presencial para renovação de reconhecimento. Na edição de 2013, foram abrangidos pelo indicador 4.529 cursos de 17 áreas, em 4.319 Unidades de Observação, em 1.025 IES, em que 11,6\% dos cursos registraram conceitos insatisfatórios.

\section{PRINCIPAIS MUDANÇAS METODOLÓGICAS DO CPC (2007-2015)}

A metodologia empregada no cálculo do CPC sofreu algumas modificações desde a sua primeira configuração (2007), tanto em relação aos componentes que o integram, como em relação aos pesos de cada insumo para a composição da nota final. O Quadro 1 exibe um panorama acerca das principais mudanças metodológicas ocorridas no indicador desde a sua criação, as quais serão detalhadas em seguida:

QUADRO 1 - Principais aspectos e mudanças do cálculo do CPC no período de 2007 a 2015

\begin{tabular}{|c|l|}
\hline ANO & \multicolumn{1}{c|}{ DESCRIÇÃo } \\
\hline \multirow{2}{*}{2007} & $\begin{array}{l}\text { 3 componentes: 1 - nota padronizada contínua do Enade (nota do Enade); 2 - nota padronizada } \\
\text { contínua do IDD (nota do IDD); 3 - nota padronizada contínua dos insumos que retratam } \\
\text { a qualidade do curso (nota dos Insumos), e seus subcomponentes: a) características de } \\
\text { infraestrutura e instalações físicas; b) recursos didático-pedagógicos; e c) características do } \\
\text { corpo docente. }\end{array}$ \\
\hline \multirow{2}{*}{2008} & $\begin{array}{l}\text { 8 componentes: 1 - Nota dos Concluintes no Enade (NC); 2 - Nota dos Ingressantes no Enade } \\
\text { (NI); 3 - Nota do Indicador de Diferença entre os Desempenhos Observado e Esperado (NIDD); } \\
4-\text { Nota de Professores Doutores (NPD); 5 - Nota de Professores Mestres (NPM); 6 - Nota de } \\
\text { Professores com Regime de Dedicação Integral ou Parcial (NPR); 7 - Nota de Infraestrutura (NF); } \\
\text { e 8 - Nota referente à Organização Didático-Pedagógica (NO). }\end{array}$ \\
\hline \multirow{2}{*}{2011} & $\begin{array}{l}7 \text { componentes: retirada a Nota dos Ingressantes no Enade (NI) do cálculo, passando a utilizar o } \\
\text { resultado do desempenho dos estudantes do Enem no cálculo do IDD; redistribuição dos pesos } \\
\text { dos componentes do CPC. }\end{array}$ \\
\hline $\begin{array}{l}\text { Alteração na utilização dos insumos do Questionário do Estudante do Enade no cálculo do CPC, } \\
\text { ampliando os itens sobre a percepção discente acerca das condições do processo formativo dos } \\
\text { cursos (de 2 para 42 itens). }\end{array}$ \\
\hline
\end{tabular}

Fonte: Adaptado de Ikuta (2016, p. 147)

Conforme observado no Quadro 1, a primeira revisão do CPC se deu em 2008 (BRASIL, 2014), por meio de uma reorganização na explicitação dos componentes da fórmula: em 2007, era inicialmente apresentada com apenas três componentes, que por sua vez continham alguns subcomponentes do funcionamento do curso (insumos); após a revisão, a fórmula se tornou mais longa, passando a exibir oito componentes. Além 
disso, também ocorreram duas mudanças importantes: alterações na ponderação adotada para esses componentes, ampliando o peso atribuído à titulação docente e diminuindo a participação do desempenho dos estudantes (BITTENCOURT et al., 2010), além da inclusão do componente da Nota de Professores Mestres na dimensão de avaliação do corpo docente.

A segunda revisão se deu em 2011, quando a Portaria Normativa n. 40/2007 foi republicada em 2010, instituindo a dispensa da participação de alunos ingressantes a partir da edição do Enade de 2011, em face da ampliação do Exame Nacional do Ensino Médio (Enem) (BRASIL, 2014), momento em que a Nota dos Ingressantes do Enade (NI) foi retirada do cálculo do CPC. Além disso, uma readequação do cálculo do IDD foi necessária, de forma a incluir o desempenho médio dos estudantes no Enem.

Em 2013, foi instituído um grupo de trabalho, composto por especialistas da área, para rever o formato do Questionário do Estudante do Enade, com a intenção de que fossem produzidos insumos mais próximos da realidade das percepções dos estudantes em relação às condições dos cursos. Dessa maneira, já na edição de 2013, foi aplicada uma nova versão do Questionário, apresentando significativas mudanças, as quais ampliaram as fontes de percepção discente de dois itens para 42, incluindo novos itens sobre Organização Didático-Pedagógica, Infraestrutura e Oportunidades de Ampliação da Formação Acadêmica e Profissional.

Nesse processo, após análises de pesquisadores e gestores do Inep, além de outros pesquisadores da área de avaliação, a forma de cálculo do CPC novamente se alterou em 2013, para adequar-se às novas fontes de percepção discente, agora disponíveis nas respostas ao Questionário. Assim, o peso de $15 \%$ referente ao total da nota do CPC dedicada à percepção discente, que era desdobrado em 7,5\% para o quesito Organização Didático-Pedagógica e 7,5\% para Infraestrutura, foi redistribuído. A nota referente à Organização Didático-Pedagógica permaneceu com o peso de 7,5\%, porém a nota relativa à Infraestrutura reduziu-se a 5\%, com o acréscimo da nota referente às Oportunidades de Ampliação da Formação Acadêmica e Profissional (2,5\%). 
O Inep, que realizou uma análise comparativa das primeiras três versões de composição do CPC (ou seja, de 2007, 2008 e 2011), defende que se mantiveram inalteradas, durante todo o percurso, as três dimensões que formam os pilares para a avaliação: desempenho dos estudantes, corpo docente e percepções discentes sobre as condições do curso (BRASIL, 2014).

\section{OS DEBATES EM TORNO DO CPC: UMA REVISÃO CRÍTICA}

Por meio do levantamento bibliográfico realizado sobre o tema, foi possível perceber que as concepções que norteiam a relação do CPC com o Sinaes e até mesmo seus próprios cálculos e mudanças metodológicas são muito discutidos e questionados, desde o seu surgimento. Nesse sentido, a fim de trazer novos questionamentos ao debate, parece importante entender o indicador de qualidade não apenas tecnicamente, mas também compreender seus processos de concepção e aplicação como resultados de ações e decisões que possuem influência de contextos políticos. Conforme afirma Barreyro (2008, p. 864, grifo da autora), “como os estatísticos nos dizem, essas construções, ponderações e escolhas também não são inocentes, neutras, nem apenas técnicas".

Desde a instituição do CPC, há uma considerável produção científica que alerta para a falta de associação desse indicador com as premissas originais do Sinaes, especialmente pela questão da diminuição das visitas presenciais nos cursos avaliados, já mencionada anteriormente, questão tida como obrigatória na Lei do Sistema. A instituição do CPC foi analisada como uma prática do MEC que sinalizou

[...] apenas uma questão operacional decorrente da implementação do Sinaes, e não uma mudança central que retoma velhas concepções e discussões sobre os modelos de avaliação da educação superior no país" (BARREYRO; ROTHEN, 2014, p. 70).

Nesse sentido, também,

Esta mudança de rumo, que passou a privilegiar a dispensa de visitas de comissões de avaliação, imprimiu um caráter assistêmico ao Sinaes, pois os reguladores passaram 
a focalizar os resultados de apenas uma de suas métricas de avaliação, o Enade, dispensando a maior parte das avaliações presenciais dos cursos e dilatando os prazos para a análise dos recredenciamentos das IES. (PEIXOTO et al., 2016, p. 499)

Sabe-se que a proposta original do Sinaes ensaiou uma grande mudança na avaliação da educação superior brasileira, especialmente na conciliação de diferentes práticas e metodologias; porém, especialmente a partir de 2008, a ênfase nos índices acabou por centrar um exame de larga escala (o Enade) como principal referência para a regulação do sistema, desvinculando-se da proposta original. Com esse movimento, os resultados da prova do Enade, que servem de base para a formulação dos conceitos do CPC e do IGC, foram ganhando autonomia e maior visibilidade que o próprio Sinaes, passando a se revestir de objetividade e colocando em xeque os métodos de autoavaliação e avaliações externas. Dias Sobrinho (2008, p. 821) indica que, nesse contexto,

[...] a avaliação institucional, que era central no Sinaes, se torna periférica [...] $\bigcirc$ Enade e o estudante passam a ser as principais fontes de informação para a formulação dos índices de qualidade.

Esse movimento aponta a centralidade e a ênfase para o uso da regulação (SOUSA; FERNANDES, 2016; LACERDA; FERRI, 2015), deixando de lado outras propostas de avaliação integrada.

A criação de indicadores para a avaliação da qualidade da educação superior, em associação a conceitos em escala numérica (tal como é o CPC), é criticada na literatura por possuir, muitas vezes, tendências exageradamente quantitativas e técnicas. Além disso, geram uma grande exposição na mídia, impactando de forma significativa na percepção da sociedade - situação em que se tornam verdadeiros selos de qualidade, cujas instituições investem pesadamente em propagandas publicitárias (marketing institucional) -, muito embora seu real significado esteja apenas nas entrelinhas dos anúncios. Nesse processo, faz-se necessário considerar 
o caráter simplificador que muitas vezes reveste os índices com uma aparência de verdades absolutas, representando o que deve ser a referência de qualidade de um curso ou de uma instituição (POLIDORI, 2009). Esses resultados acabam legitimando as práticas envolvidas, pois:

[...] comparações e resultados simplificados não são um mal em si, mas, dentro de uma lógica mercadológica, funcionam apenas como um fator de concorrência mercantil, em oposição à possível colaboração e troca de experiências visando a melhoria de qualidade. (BARREYRO; ROTHEN, 2011, p. 27)

A emergência da instituição do CPC também rendeu diversos questionamentos envolvendo a construção, o cálculo do indicador e as implicações das escolhas metodológicas para a definição de seus componentes. Schwartzman (2008), Barreyro (2008) e Barreyro e Rothen (2011) questionaram esses aspectos, à época de sua criação, principalmente em relação aos critérios escolhidos para o peso de cada componente na nota final, além da ausência de documentos que fornecessem informações transparentes e sistematizadas sobre as fórmulas e as mudanças metodológicas. Nesse âmbito, há dúvidas sobre sua consistência técnica, resumindo a qualidade de cursos a médias ponderadas de variáveis pouco comparáveis entre si (BARREYRO; ROTHEN, 2011).

As inúmeras críticas de pesquisadores, técnicos e especialistas da área de avaliação da educação superior levaram o Inep a revisões metodológicas no cálculo do CPC, conforme observado anteriormente no Quadro 1. Inclusive, especialistas do próprio Instituto, em estudo de 2009, avaliaram que "por ser um indicador composto, o CPC tem recebido a crítica de juntar coisas muito diferentes e, assim, ser um indicador sem sentido" (FERNANDES et al., 2009, p. 17).

Bittencourt et al. (2010) avaliaram que os pesos atribuídos a cada componente do CPC merecem reflexões mais aprofundadas, uma vez que mudanças nesses pesos podem impactar significativamente as notas do indicador, especialmente considerando a configuração de certos tipos de IES. Segundo a análise dos autores, mediante estudo comparati- 
vo, algumas IES são mais sensíveis, por exemplo, aos itens de desempenho dos estudantes, como é o caso das universidades federais; e outras, como as universidades privadas, são mais sensíveis aos itens de infraestrutura e instalações físicas, que possuem peso menor na fórmula do CPC. Ou seja, "como existem pontos fortes e fracos nos dois tipos de universidade, a distribuição dos pesos poderá ser favorável ou desfavorável a um grupo de universidades" (BITTENCOURT et al., 2010, p. 161).

Outro ponto importante, com relação à formulação do CPC, refere-se aos processos de ponderação e padronização das notas de cada insumo. Observa-se que há grande concentração dos cursos avaliados em torno do Conceito 3 (considerando a escala possível de 1 a 5), pois essa é uma característica intrínseca à sua metodologia. $\mathrm{O}$ recurso estatístico de afastamento padronizado, utilizado para a obtenção das notas de cada componente, acaba gerando maior homogeneização na distribuição das notas, concentrando-as especialmente em torno da faixa 3 do indicador, o que também ocorre com outros indicadores produzidos no âmbito do Sinaes (BITTENCOURT et al., 2008). No entanto, verifica-se também que esse é um processo em que

[...] a nota atribuída a cada um dos insumos não é a exata fotografia do curso da instituição, senão uma ponderação das notas obtidas em cada insumo do curso, confrontada com o comportamento nacional naquela área de avaliação. (NUNES; FERNANDES; ALBRECHT, 2014, p. 31)

Ou seja, as notas atribuídas aos insumos não dependem, exclusiva e diretamente, das respostas dos alunos e/ou condições da IES em questão - dependem também das respostas dos alunos e/ou condições das demais IES que oferecem cursos daquela área avaliada. Isso impacta de forma significativa na análise desses resultados, que podem não refletir todas as especificidades de cada curso avaliado.

O CPC também recebe críticas por se basear de forma demasiada nos insumos do Enade, já que, em 2014, 55\% da nota final do CPC referia-se única e exclusivamente ao desempenho dos estudantes, e mais $15 \%$ estavam relacionados 
às respostas dos discentes em relação a condições físicas e pedagógicas dos cursos. Se os percentuais forem somados, 70\% da nota do CPC estava inteiramente relacionada, de alguma maneira, aos discentes.

Soma-se a essa situação o agravante do alto grau de subjetividade intrínseco às respostas de discentes, pois "o resultado na prova depende também da motivação e preparação específica dos estudantes para realizar o exame, das condições da aplicação, da sorte, etc.” (FERNANDES et al., 2009, p. 7). Segundo os mesmos autores, ainda, outros fatores podem enviesar tanto a nota dos concluintes de um curso (alguns cursos, por exemplo, atraem bons alunos), quanto a nota do IDD, que também compõe o CPC. Os insumos obtidos por meio das respostas dos alunos para a avaliação dos aspectos físicos e pedagógicos também são questionados, inclusive pela própria formulação das perguntas contidas no Questionário do Estudante do Enade, em que pode ocorrer um conflito entre o enunciado da questão e o que é interpretado e respondido pelos estudantes (NUNES; FERNANDES; ALBRECHT, 2014; LACERDA; FERRI, 2015).

Diante desse quadro, considera-se que

[...] não há teoria educacional que sustente que o desempenho de um estudante numa prova seja plena garantia de aprendizagem, nem de que o resultado de um conjunto de estudantes num exame seja igual à qualidade de um curso. (DIAS SOBRINHO, 2008, p. 822)

Essa condição revela uma grande limitação do CPC, pois, evidentemente, a percepção estudantil é uma dimensão válida e útil para a avaliação; no entanto,

[...] tomá-la como referência para a regulação do sistema parece absurdo [...] assume-se que a avaliação discente é suficiente, contrariando a prática do Ministério de conduzir a avaliação dos insumos por especialistas de áreas ou de avaliação. (BARREYRO; ROTHEN, 2011, p. 31)

Mais recentemente, em 2013, conforme observado, o CPC ampliou ainda mais a participação dessas respostas em sua nota final, pois passou a incluir outro componente desse segmento 
(itens do Questionário Enade sobre o tema "Oportunidades de Ampliação da Formação Acadêmica e Profissional”).

Lacerda e Ferri (2015) também sugeriram mudanças no CPC, principalmente em relação à revisão de questões existentes no Questionário do Estudante no Enade e à construção de CPCs específicos, que levem em consideração a heterogeneidade das organizações acadêmicas e categorias administrativas das IES. Nesse sentido, seria importante

\section{[...] dispor de um conjunto amplo e diverso de indicado- res de avaliação para a qualidade institucional, e assim res- peitar a diversidade do sistema de educação superior do Brasil. (LACERDA; FERRI, 2015, p. 142, grifo dos autores)}

Soma-se a essa questão da heterogeneidade o momento da divulgação dos resultados do CPC (realizada anualmente pelo Inep). Os dados são disponibilizados por meio de planilha eletrônica, em formato Microsoft Excel, contendo a nota final de cada Unidade de Observação, bem como as notas obtidas de cada componente. Entretanto, a nota dos cursos que possuem oferta nas modalidades presencial e a distância é divulgada de maneira unificada, considerando a soma dos estudantes das duas modalidades e seus respectivos resultados (BRASIL, 2016a). Tendo em vista que a modalidade de educação a distância é um segmento em franca expansão no país, e que chegou, em 2014, a uma participação de 17,1\% no total de matrículas da educação superior (BRASIL, 2016b), tal situação pode dificultar, em certa medida, a análise individual das particularidades de cada curso.

Além disso, as principais mudanças de metodologia, ocorridas nos anos de 2008, 2011 e 2013, bem como o próprio processo de padronização das notas desse indicador, ainda revelam a impossibilidade de comparações anuais e produção de séries históricas. Além da limitação em relação aos resultados do CPC, que são divulgados anualmente (e que possuem fórmulas diferentes), há também a restrição em torno das áreas que são avaliadas no Enade. São realizadas avaliações apenas a cada três anos para cada conjunto de cursos, ou seja: o CPC de 2014 avaliou as mesmas áreas de cursos, em que pesem às mudanças no cálculo, nas edições 
de 2008 e 2011. No entanto, em razão de sua construção metodológica, somente é possível comparar os resultados de avaliação dos cursos em uma mesma edição (ano) do indicador.

Com relação à transparência das informações, vale ressaltar, em uma perspectiva mais ampla, que também são apontados problemas em relação à divulgação do andamento dos processos integrais de avaliação de cursos no Sinaes. Sabe-se que os cursos que tenham obtido CPCs insatisfatórios, a cada avaliação, necessitam passar por avaliações presenciais. No entanto, não são encontrados dados oficiais e sistematizados sobre a quantidade de cursos que passam por avaliações presenciais anualmente, nem quantos são oficialmente suspensos com base nas medidas de regulação e supervisão por parte do MEC, cujas ações deveriam ser totalmente transparentes para a sociedade (SOUSA; FERNANDES, 2016).

Ressaltadas as limitações sobre o CPC, identificadas no debate científico, é importante também apontar suas possibilidades, ou potencialidades, de forma a estabelecer um debate justo, que englobe as diferentes dimensões do tema. Nesse sentido, é importante salientar que o CPC possui, atualmente, um peso significativo enquanto indicador de qualidade vigente no sistema de avaliação da educação superior brasileira, considerando seu impacto para a renovação de reconhecimento dos cursos - especialmente, diante de um segmento que se caracterizou pela grande expansão de cursos, matrículas e instituições, majoritariamente no setor privado, processo do qual surgiu a necessidade intrínseca de avaliação e controle da qualidade.

Identificou-se um complexo quadro de dualidade do sistema de avaliação, diante do já consolidado setor privado de educação superior, em que $87,4 \%$ das IES do sistema são privadas, "a despeito do fato de que nosso arcabouço regulatório oscila entre apoiar o setor privado e, ao mesmo tempo, estigmatizá-lo" (NUNES; FERNANDES; ALBRECHT, 2014, p. 4). De fato, no que tange à busca pela qualidade, os processos de avaliação são de grande importância em face da expansão da esfera privada, gerada no bojo do atendimento aos interesses do mercado. Sem dúvidas, é preciso haver certo controle e regulação para assegurar que essas IES cumpram suas responsabilidades e funções sociais. 
A ênfase nos índices para regular o sistema é uma dimensão muito importante, em especial, para as IES privadas, pois além da regulação que é exercida como condição e controle para a oferta de vagas (podendo resultar em processos que visam firmar compromissos de aperfeiçoamentos), os resultados também balizam a participação dessas IES em diversas políticas fundamentais para seu funcionamento e manutenção, como o Programa Universidade para Todos (ProUni), o Fundo de Financiamento Estudantil (Fies) e a obtenção de créditos junto ao Banco Nacional de Desenvolvimento Econômico e Social (BNDES) (BARREYRO; ROTHEN, 2014).

Além disso, como os resultados são divulgados para toda a sociedade brasileira, as notas do CPC, bem como dos outros indicadores de qualidade divulgados pelo Inep a partir da realização da prova do Enade, se por um lado favorecem a construção de rankings e estimulam a competitividade entre as IES, também podem ser utilizados para outros tipos de comparação entre as IES e os cursos. O uso de um indicador de caráter quantitativo, embora encontre-se o risco de não refletir a totalidade do que se pretende avaliar, pode ser uma ferramenta útil para a obtenção de estatísticas educacionais, possibilitando a realização de pesquisas e comparações mais abrangentes, em âmbito nacional e mundial.

Os indicadores, ou mesmo um sistema de indicadores, têm sido amplamente enfatizados e utilizados para analisar o desenvolvimento, o desempenho e a qualidade dos sistemas nacionais de educação (BERTOLIN, 2007); ainda que, para o autor, a qualidade da educação superior deva ser considerada um conceito múltiplo, não podendo ser avaliada por apenas um indicador isolado. Nesse âmbito,

[...] não há dúvida de que avaliar cursos e instituições da educação superior, inclusive por meio de exames aplicados aos estudantes como um dos instrumentos de um sistema mais amplo, é importante. (BERTOLIN; MARCON, 2015, p. 119)

No entanto, há uma percepção crítica a respeito de se tornarem automaticamente sinônimos de qualidade da educação superior. 
Nesse sentido, apesar de sofrer inúmeras críticas, é importante entender as potencialidades de uma avaliação com base em exames ou provas de larga escala, considerando a grande estrutura da educação superior no país. Assim, o Enade constituiu-se como uma política relevante para subsidiar informações em relação às políticas públicas e para o monitoramento das IES no país; por outro lado, concorda-se que "agregar os resultados do Enade e das avaliações interna e externa seria, sem dúvida, um passo importante para a retomada da proposta original do Sinaes" (BITTENCOURT; CASARTELLI; RODRIGUES, 2009, p. 679).

O próprio Inep indicou, como recomendações para o cálculo do CPC nos próximos anos,

[...] empregar uma única metodologia de cálculo para os indicadores durante os três anos de duração do ciclo de avaliação do Sinaes, para que todas as áreas de conhecimento sejam avaliadas de forma semelhante. (BRASIL, 2012, p. 13)

além de apontar a necessidade de pesquisas futuras que visem melhorar "a qualidade dos insumos utilizados no CPC" (BRASIL, 2012, p. 13). Apesar disso, o órgão sinaliza, acerca da necessidade de uniformizar os pressupostos metodológicos, que o CPC se encontra, ainda, em processo de transformação e aprimoramento, assim como diversos aspectos do próprio Sinaes.

No decorrer do histórico das políticas voltadas para avaliação da educação superior brasileira, é possível perceber que, inclusive no próprio Sinaes, foi dada ênfase a um paradigma que envolve mecanismos de controle e gestão, mais do que propriamente a discussão sobre qualidade da educação e processos formativos. Assim, concorda-se que:

Obviamente, sempre haverá contradições e imperfeições num sistema de avaliação, pois se trata de um fenômeno social e construção histórica. Nisso consiste a riqueza da avaliação: nunca está acabada, nem fechada às diferentes interpretações e aos distintos interesses de grupos, não é neutra nem detentora da verdade absoluta, mas precisa se esforçar para ser justa e socialmente eficaz. (DIAS SOBRINHO, 2010, p. 223) 
A questão, por um lado, parece não girar em torno da necessidade de avaliação da qualidade, o que se constitui como uma realidade, pois auxilia a filtrar a complexa e diversificada rede educacional (especialmente em um país extremamente heterogêneo em termos econômicos, sociais e regionais como o Brasil). Por outro lado, verifica-se a necessidade de uma análise cuidadosa em torno da metodologia empregada no processo de avaliação; nesse caso, entender os riscos e vantagens do peso dos elementos quantitativos nos indicadores utilizados para a avaliação da educação superior, tal como existem hoje.

\section{CONSIDERAÇÕES FINAIS}

As discussões levantadas neste artigo suscitaram diversas reflexões, revelando que a concepção oficial de qualidade na educação superior, refletida no indicador do Conceito Preliminar de Curso é apenas uma entre as diversas concepções que poderiam estar relacionadas ao termo - que, por sua vez, é conhecido pela falta de construção de consensos no âmbito do debate educacional, não apenas brasileiro, mas mundial. Entretanto, entende-se que esse caráter polissêmico envolvido não deve ser utilizado como pretexto para fugir da discussão em torno de seus significados, pois

[...] em qualquer contexto social, político e econômico, uma determinada concepção de qualidade ganha prevalência sobre as demais sem, contudo, implicar a extinção de outras com as quais convive. (SOUSA, 2009, p. 244)

É possível perceber que, no Sinaes, apesar de ser uma política constituída por mecanismos diversificados de avaliação e considerar diferentes dimensões - entre elas a avaliação institucional interna e externa -, ficou marcado, sobretudo, um deslocamento de sua proposta inicial, para uma tendência do uso de métodos quantitativos na avaliação da qualidade da educação superior. Baseando-se nos três eixos principais de avaliação do sistema, foram adotados três indicadores de qualidade: o IGC para as instituições, o CPC para os cursos e o Conceito Enade para o desempenho dos estudantes. 
A ampla utilização desses resultados, tanto pelo sistema educacional como pelos órgãos midiáticos, favoreceu a criação de rankings e um ambiente de competitividade entre as IES. As notas, em escala numérica, se constituíram como um dos reflexos do que é qualidade em uma instituição, um curso ou do desempenho dos alunos, com alto impacto para a percepção e compreensão da sociedade acerca dessa qualidade. Sobre esse aspecto, é importante ressaltar que o tema da qualidade da educação superior é conhecido por sua diversidade conceitual, em um campo que ainda configura espaço de muitos estudos e debates, nos quais são construídos poucos consensos. Conforme indica Bertolin, identifica-se uma situação em que "o entendimento da qualidade é inexoravelmente subjetivo, porque depende fundamentalmente das concepções de mundo e de educação superior de quem o emite" (BERTOLIN, 2009, p. 146).

Diante dos levantamentos realizados neste texto, verificou-se que é extremamente importante problematizar as potencialidades e fragilidades do CPC enquanto indicador de qualidade de cursos superiores, observando sua concepção e sua utilização como um resultado de decisões que não refletem apenas uma construção técnica.

O debate levantado em torno do indicador revela algumas fragilidades que precisam ser refletidas, tais como: 1) a dispensa automática das avaliações presenciais dos cursos, na qual é importante problematizar esses processos tal como existem hoje - inclusive, com mais estudos a esse respeito -, tendo em vista a questão da viabilidade, ou não, de realizar tais avaliações para todos os cursos em cada ciclo, considerando as já mencionadas dificuldades do MEC e do Inep de operacionalizá-las; 2) as mudanças na metodologia de cálculo e os critérios de seleção e ponderação das variáveis, que geram questionamentos sobre a consistência técnica do indicador, a implicação da escolha dos componentes em relação aos objetivos de avaliação e também sobre a comparabilidade dos resultados; 3) a homogeneização excessiva das notas, que inviabiliza análises acerca de algumas especificidades de cada curso avaliado; 4) a alta participação das respostas dos estudantes na nota final, a despeito das subjetividades 
intrínsecas a esse modo de avaliação; 6) a questão da heterogeneidade de IES e cursos existentes no país, que é desconsiderada; 7) a periodicidade dos resultados, cujos cursos de cada área de conhecimento são avaliados apenas trienalmente, seguindo o calendário do Enade; e 8) a falta de transparência na divulgação para a sociedade dos resultados do processo integral de avaliação de cursos no Sinaes.

Todavia, neste trabalho, considera-se que o ato de avaliar é um processo de construção de juízos de valores para tomadas de decisões, constituindo um espaço e um processo indispensável na perspectiva da melhoria da qualidade das atividades relacionadas à educação superior. Ao mesmo tempo, buscou-se evidenciar durante o texto que, enquanto o indicador possui um caráter significativo para a operacionalização da avaliação de cursos de graduação no Brasil, constituindo-se como uma das principais referências para a formulação de estatísticas educacionais e políticas públicas - e sendo essa uma responsabilidade gigantesca, considerando os mais de 32 mil cursos existentes no país -, não faltam críticas à sua formulação, aplicação e à (falta de?) integração com os demais aspectos idealizados pelo Sinaes. Com relação a esse assunto, parece urgente a retomada da proposta original do Sistema, ou seja, no sentido de conciliar as diferentes modalidades de avaliações, buscando o equilíbrio entre métodos quantitativos e qualitativos - por mais desafiador que se configure esse caminho.

Na relação intrínseca em que se constitui a construção de metodologias de avaliação e as concepções de qualidade, encontra-se um processo corrente e em transformação na agenda brasileira. A história de constituição dos processos de avaliação no país é marcada por diversos debates, principalmente em torno da própria concepção de avaliação a ser empregada, e sobre qual instância deve ser responsável por realizá-la, sendo essa uma discussão diversificada de acordo com os interesses dos grupos e dos atores envolvidos. Inclusive, a disputa pelo conceito de qualidade da educação superior acaba marcada por potencializar esse jogo entre os segmentos sociais interessados (PEIXOTO et al., 2016). Nessa linha de pensamento, Oliveira, Fonseca e Amaral (2006) 
postulam que a avaliação na educação superior no país ainda possui muitos desafios a serem superados, para que seus instrumentos atinjam os objetivos proclamados no sentido de provocar mudanças qualitativas no âmbito educacional.

Para além das críticas, emerge neste trabalho a importância da reflexão sobre que tipo de qualidade se está medindo, e a importância de observar de que forma a acepção que é dada a esse conceito relaciona-se com o modelo de avaliação proposto. De acordo com as palavras de Dias Sobrinho (2008), a noção de qualidade, portanto, acaba atrelada ao contexto e às práticas vigentes. Nessa perspectiva, torna-se relevante - e parte de uma análise coerente -, o exercício de descortinar, o máximo possível, quais são as questões técnicas, políticas, ideológicas, partes interessadas, jogos de poder e atores envolvidos nas instâncias decisórias das práticas de avaliação da educação superior brasileira.

\section{REFERÊNCIAS}

BARREYRO, Gladys Beatriz. De exames, rankings e mídia. Avaliação, Sorocaba, v. 13 , n. 3 , p. $863-8$, nov. 2008.

BARREYRO, Gladys Beatriz; ROTHEN, José Carlos. “Sinaes” contraditórios: considerações sobre a elaboração e implantação do Sistema Nacional de Avaliação da Educação Superior. Educação \& Sociedade, Campinas, v. 27, n. 96, p. 955-77, out. 2006. Edição Especial.

BARREYRO, Gladys Beatriz; ROTHEN, José Carlos. Percurso da avaliação da educação superior nos Governos Lula. Educação e Pesquisa, São Paulo, v. 40, n. 1, p. 61-76, jan./mar. 2014.

BRASIL. Lei n. 10.861, de 14 de Abril de 2004. Institui o Sistema Nacional de Avaliação da Educação Superior - Sinaes e dá outras providências. Diário Oficial [da] República Federativa do Brasil, Brasília, DF, 15 abr. 2004. Disponível em: <http://www.planalto.gov.br/ccivil_03/_ato2004-2006/2004/lei/110.861. htm>. Acesso em: 21 jun. 2016.

BRASIL. Decreto n. 5.773, de 9 de maio de 2006. Dispõe sobre o exercício das funções de regulação, supervisão e avaliação de instituições de educação superior e cursos superiores de graduação e sequenciais no sistema federal de ensino. Diário Oficial [da] República Federativa do Brasil, Brasília, DF, 10 maio 2006. Disponível em: <http://www2.mec.gov.br/sapiens/portarias/dec5773. htm>. Acesso em: 15 jun. 2016. 
BRASIL. Instituto Nacional de Estudos e Pesquisas Educacionais Anísio Teixeira. Nota Técnica n. 29/2012: cálculo do Conceito Preliminar de Curso (CPC) referente ao ano de 2011. Brasília, DF: Inep, out. 2012. Disponível em: $<$ http://download.inep.gov.br/educacao_superior/enade/notas_tecnicas/2011/ nota_tecnica_indicadores_2011_2.pdf>. Acesso em: 17 jun. 2016.

BRASIL. Instituto Nacional de Estudos e Pesquisas Educacionais Anísio Teixeira. Nota Metodológica: indicadores de qualidade da educação superior 2012. Brasília, DF, Inep, out. 2013a. Disponível em: <http://download.inep. gov.br/ educacao_superior/enade/notas_tecnicas/2012/nota_metodologica_ indicadores_2012.pdf $>$. Acesso em: 28 jun. 2016.

BRASIL. Instituto Nacional de Estudos e Pesquisas Educacionais Anísio Teixeira. Medidas de Regulação e Supervisão - CPC e IGC 2012. Brasília, DF, Inep, 2013b. Disponível em: <http://download.inep.gov.br/educacao_superior/ enade/ documentos/2013/regulacao_supervisao_medidas.pdf>. Acesso em: 4 dez. 2015.

BRASIL. Instituto Nacional de Estudos e Pesquisas Educacionais Anísio Teixeira. Nota Técnica n. 70: utilização dos insumos do questionário do estudante aplicado em 2013. Brasília, DF, Inep, out. 2014. Disponível em: $<$ http://download. inep.gov.br/educacao_superior/enade/notas_tecnicas/2013/ nota_tecnica_n_70_2014_utilizacao_insumos_questionario_estudante_2013. pdf $>$. Acesso em: 4 maio 2016.

BRASIL. Instituto Nacional de Estudos e Pesquisas Educacionais Anísio Teixeira. Nota Técnica n. 58: cálculo do Conceito Preliminar de Curso 2014. Brasília, DF, Inep, 2015. Disponível em: <http://download.inep.gov.br/ educacao_superior/enade/ notas_tecnicas/2014nota_tecnica_daes_n582015_ calculo_do_cpc2014.pdf>. Acesso em: 23 jun. 2016.

BRASIL. Instituto Nacional de Estudos e Pesquisas Educacionais Anísio Teixeira. Conceito Preliminar de Curso - CPC. Brasília, DF: Inep, 2016a. Disponível em: <http://portal.inep.gov. br/educacao-superior/indicadores/ cpc >. Acesso em: 28 jun. 2016.

BRASIL. Instituto Nacional de Estudos e Pesquisas Educacionais Anísio Teixeira. Sinopses estatísticas da educação superior: graduação 2014. Brasília, DF: Inep, 2016b. Disponível em: <http://portal.inep.gov.br/superiorcensosuperior-sinopse>. Acesso em: 21 jun. 2016.

BRASIL. Ministério da Educação. Portaria Normativa n. 40, de 12 de dezembro de 2007. Institui o e-MEC, sistema eletrônico de fluxo de trabalho e gerenciamento de informações relativas aos processos de regulação da educação superior no sistema federal de educação. Diário Oficial [da] República Federativa do Brasil, Brasília, DF, 12 dez. 2007. Disponível em: <http://uab. capes. gov.br/images/stories/downloads/legislacao/portarian40.pdf $>$. Acesso em: 17 ago. 2016. 
BRASIL. Ministério da Educação. Portaria Normativa n. 4, de 5 de agosto de 2008. Regulamenta a aplicação do conceito preliminar de cursos superiores - CPC, para fins dos processos de renovação de reconhecimento respectivos, no âmbito do ciclo avaliativo do Sinaes. Diário Oficial [da] República Federativa do Brasil, Brasília, DF, 6 ago. 2008. Disponível em: <http://download.inep. gov.br/download/superior/condicoesdeensino/Portaria_N_4_de_5_de_ agosto_2008.pdf>. Acesso em: 31 maio 2016.

BRASIL. Ministério da Educação. Portaria Normativa n. 40, de 29 de dezembro de 2010. Institui o e-MEC, sistema eletrônico de fluxo de trabalho e gerenciamento de informações relativas aos processos de regulação, avaliação e supervisão da educação superior no sistema federal de educação, o Cadastro e-MEC de Instituições e Cursos Superiores e consolida disposições sobre indicadores de qualidade, banco de avaliadores (Basis) e o Exame Nacional de Desempenho de Estudantes (Enade) e outras disposições. Diário Oficial [da] República Federativa do Brasil, Brasília, DF, 29 dez. 2010. Disponível em: <http://download.inep.gov.br/download/superior/ 2011/portaria_ normativa_n40_12_dezembro_2007.pdf>. Acesso em: 10 maio 2016.

BERTOLIN, Júlio Cesar Godoy. Indicadores em nível de sistema para avaliar o desenvolvimento e a qualidade da educação superior brasileira. Avaliação, Sorocaba, v. 12, n. 2, p. 309-31, jun. 2007.

BERTOLIN, Júlio Cesar Godoy. Qualidade em educação superior: da diversidade de concepções à inexorável subjetividade conceitual. Avaliação, Sorocaba, v. 14, n. 1, p. 127-49, mar. 2009.

BERTOLIN, Júlio Cesar Godoy; MARCON, Telmo. O (des)entendimento de qualidade na educação superior brasileira: das quimeras do provão e do Enade à realidade do capital cultural dos estudantes. Avaliação, Sorocaba, v. 20, n. 1, p. 105-22, mar. 2015.

BITTENCOURT, Hélio Radke; CASARTELLI, Alam de Oliveira; RODRIGUES, Alziro César de Morais. Sobre o Índice Geral de Cursos (IGC). Avaliação, Sorocaba, v. 14, n. 3, p. 667-82, nov. 2009.

BITTENCOURT, Hélio Radke; CASARTELLI, Alam de Oliveira; RODRIGUES, Alziro Cesar de Morais; VIALI, Lorí. Uma análise da relação entre os conceitos Enade e IDD. Estudos em Avaliação Educacional, São Paulo, v. 19, n. 40, p. 247-62, maio/ago. 2008.

BITTENCOURT, Hélio Radke; CASARTELLI, Alam de Oliveira; RODRIGUES, Alziro Cesar de Morais; VIALI, Lorí. Mudanças nos pesos do CPC e seu impacto nos resultados de avaliação em universidades federais e privadas. Avaliação, Sorocaba, v. 15, n. 3, p. 147-66, nov. 2010.

DIAS SOBRINHO, José. Qualidade, avaliação: do Sinaes a índices. Avaliação, Sorocaba, v. 13, n. 3, p. 817-25, nov. 2008.

DIAS SOBRINHO, José. Avaliação e transformações da educação superior brasileira (1995-2009): do provão ao Sinaes. Avaliação, Sorocaba, v. 15, n. 1, p. 195-224, mar. 2010. 
FERNANDES, Reynaldo; PAZELLO, Elaine Toldo; LEITÃO, Thiago Miguel Sabino de Pereira; MORICONI, Gabriela Miranda. Avaliação de cursos na educação superior: a função e a mecânica do Conceito Preliminar de Curso. Brasília, DF, Inep, 2009. (Textos para discussão, n. 32).

IKUTA, Camila Yuri Santana. A qualidade no Programa Universidade para Todos (ProUni) segundo os resultados de avaliação de cursos do Sistema Nacional de Avaliação da Educação Superior (Sinaes). 2016. Dissertação (Mestrado) - Programa de Pós-Graduação em Educação, Universidade de São Paulo, São Paulo, 2016.

LACERDA, Leo Lynce Valle de. Sinaes, teoria e prática: pressupostos epistemológicos em oposição. Avaliação, Sorocaba, v. 20, n. 1, p. 87-104, mar. 2015.

LACERDA, Leo Lynce Valle de; FERRI, Cássia. Relações entre indicadores de qualidade de ensino e desempenho de estudantes dos cursos de Pedagogia do Brasil no Exame Nacional de Desempenho dos Estudantes. Revista Brasileira de Estudos Pedagógicos, Brasília, DF, v. 96, n. 242, p. 129-45, jan./abr. 2015.

NUNES, Edson de Oliveira; FERNANDES, Ivanildo; ALBRECHT, Julia. Regulação e ensino superior no Brasil. Rio de Janeiro: Observatório Universitário, 2014. (Documento de Trabalho, n. 112). Disponível em: $<$ http://www.observatoriouniversitario.org.br/documentos_de_trabalho/ documentos_de_trabalho_112.pdf>. Acesso em: 7 jun. 2016.

OLIVEIRA, João Ferreira de; FONSECA, Marília; AMARAL, Nelson Cardoso. Avaliação, desenvolvimento institucional e qualidade do trabalho acadêmico. Educação em Revista, Curitiba, n. 28, p. 71-87, 2006.

PEIXOTO, Maria do Carmo Lacerda; TAVARES, Maria das Graças Medeiros; ROBL, Fabiane; FERNANDES, Ivanildo. A disputa pela concepção de qualidade na educação superior do Brasil: outras referências. In: SEMINÁRIO NACIONAL UNIVERSITAS/ BR, 14., 2016, Maringá. Anais... Maringá: UEM, 2016. Disponível em: <http://www.ppe.uem.br/xxivuniversitas/anais/ trabalhos/e_3/3-003.pdf>. Acesso em: 13 maio 2016.

POLIDORI, Marlis Morosini. Políticas de avaliação da educação superior brasileira: Provão, Sinaes, IDD, CPC, IGC e outros índices. Avaliação, Sorocaba, v. 14, n. 2, p. 439-52, jul. 2009.

ROTHEN, José Carlos; BARREYRO, Gladys Beatriz. Avaliação da educação superior no segundo governo Lula: "Provão II" ou reedição de velhas práticas?. Educação \& Sociedade, Campinas, v. 32, n. 114, p. 21-38, jan./mar. 2011.

SCHWARTZMAN, Simon. O "conceito preliminar" e as boas práticas de avaliação do ensino superior. Revista da Associação Brasileira de Mantenedoras de Ensino Superior, Brasília, DF, n. 38, p. 9-32, dez. 2008.

SOUSA, José Vieira de. Qualidade na educação superior: lugar e sentido na relação público-privado. Cadernos CEDES, Campinas, v. 29, n. 78, p. 242-56, maio/ago. 2009. 
SOUSA, José Vieira de; FERNANDES, Ivanildo Ramos. Emancipação e avaliação regulatória no sistema federal de ensino. In: SEMINÁRIO NACIONAL UNIVERSITAS/BR, 14., 2016, Maringá. Anais... Maringá: UEM, 2016. Disponível em: <http://www.ppe.uem.br/xxivuniversitas/ anais/ trabalhos/e_3/3-010.pdf > . Acesso em: 22 jun. 2016.

\section{CAMILA YURI SANTANA IKUTA}

Mestre em Educação pela Faculdade de Educação da Universidade de São Paulo (FE/USP). Assessora Técnica do Departamento Intersindical de Estatísticas e Estudos Socioeconômicos (DIEESE), São Paulo, São Paulo, Brasil camila.ikuta@gmail.com 